\title{
AFINIDADES ELETIVAS ENTRE A TEORIA CRÍTICA DA SOCIEDADE E A PSICOLOGIA DA LIBERTAÇÃO: CONTRIBUIÇÕES PARA UMA FORMAÇÃO CRÍTICA EM PSICOLOGIA
}

\section{STEFANIE DE ALMEIDA MACÊDO E THAÍS DE ALMEIDA SANTOS ${ }^{1}$}

RESUMO: O objetivo deste trabalho é apresentar as possibilidades de uma formação crítica em psicologia a partir das contribuições da Teoria Crítica da Sociedade e da Psicologia da Libertação. Para tal, debruçamo-nos sobre as proposições de Marcuse, Horkheimer e Adorno na avaliação do compromisso social da ciência e da educação, utilizando suas reflexões como guia para uma análise crítica da relação entre psicologia e barbárie. Também consideramos Martin-Baró como figura essencial para contextualização da conjuntura latino-americana neste debate, sobretudo no que se refere às suas reflexões sobre a universidade e o papel social do psicólogo. Nossa tese é a de que uma formação crítica é imprescindível para o combate à barbárie das práticas psicológicas.

PALAVRAS-CHAVE: emancipação; conscientização; formação em Psicologia.

\begin{abstract}
This paper aims to present the possibilities of a critical graduate degree in psychology throughout Critical Social Theory and Liberation Psychology's contributions. For this purpose, we turn to Marcuse, Horkheimer, and Adorno's prepositions in the evaluation of the social commitment of science and education, by using their reflection as a guide to a critical analysis of the relationship between psychology and barbarism. We also consider Martín-Baró as an essential figure to contextualize Latin American's social scenario in this debate, especially his considerations about the university and psychologists' social role. Our thesis is that a critical graduate degree is indispensable for the struggle against the barbarism in psychological practices.
\end{abstract}

KEYWORDS: emancipation; conscientization; graduate degree in Psychology. 
De te fabula narratur.

(Horacio)

Na América Latina, a realidade da psicologia enquanto ciência e profissão está vinculada a um contexto sociopolítico demarcado pela violação dos direitos humanos. Inserida em uma sociedade de classes na qual o descompasso entre o desenvolvimento tecnológico e a autorrealização dos indivíduos se intensifica, a psicologia lida com um cenário ditado pela desigualdade e violência institucionalizada. Desta forma, confirmamos a presentificação da noção de barbárie desenvolvida por Theodor Adorno (1995) quando percebemos que, ainda hoje, os filhos daqueles que fabricam bombas passam fome. Nessa conjuntura, algumas reflexões se tornam imperativas: quais as possibilidades de intervenção psicológica? Qual psicologia contempla essa realidade? Qual formação contempla esta psicologia?

Por meio de uma aproximação entre a teoria crítica da sociedade e a psicologia da libertação latino-americana, almejamos refletir sobre o compromisso social da psicologia inserida neste cenário e a formação de psicólogos após o totalitarismo que assolou a América Latina. Assim como Adorno refletiu sobre a necessidade de romper com o ciclo de barbárie para uma educação após Auschwitz, o imperativo crítico de Ignácio Martin-Baró nos oferece subsídio para pensar o papel da crítica na psicologia após regimes ditatoriais e em um contexto calcado pela expansão imperialista. Dessa maneira, propomos-nos a pensar sobre os caminhos e descaminhos de uma formação emancipatória capaz de transcender a realidade reificada do capitalismo tardio mediante a adoção de "uma postura ético-política em direção ao compromisso da psicologia com as categorias da vida política como a democracia, a justiça e o viver bem sem nenhum tipo de discriminação" (Cuellar, 2015, p. 19; tradução nossa). Tendo como referencial teórico as contribuições frankfurtianas e latino-americanas em contraste com a realidade brasileira, apresentamos os temas: teoria crítica e psicologia; ciência e responsabilidade social; psicologia e barbárie; enfrentando a miséria da psicologia; psicologia - para quê?

\section{Teoria Crítica e Psicologia}

Fundado em 1923, em Frankfurt, por iniciativa do economista Felix Weil, o Instituto de Pesquisa Social se propunha a investigações científicas a partir das elaborações de Karl 
Marx em um cenário de forte repulsa ao comunismo. Em 1930, Max Horkheimer assume a direção do Instituto, oferecendo as bases do que convencionou-se chamar de teoria crítica: um trabalho coletivo interdisciplinar partindo da reflexão marxiana (Nobre, 2004). Por meio de uma crítica à racionalização extrema na sociedade industrial, os teóricos críticos abordaram temas como nazismo, novos métodos de pesquisa, capitalismo e estado de bem-estar social e papel da ciência e da técnica. De um modo geral, sua intervenção político-intelectual vinculou-se ao cenário do pós-guerra alemão, mas seu caráter de denúncia das forças mantenedoras da injustiça social ofereceram subsídio para se pensar diversos cenários históricos, superando um modelo teórico meramente descritivo e instigando a mudança social (Rush, 2008). Sua atuação fundamenta-se em duas bases: a orientação para a emancipação e o comportamento crítico, que

significa, antes de mais nada, dizer o que é em vista do que ainda não é mas pode ser. Note-se, portanto, que não se trata de um ponto de vista utópico, no sentido de irrealizável ou inalcançável, mas de enxergar no mundo real as suas potencialidades melhores, de compreender o que é tendo em vista o melhor que ele traz embutido em si. Nesse primeiro sentido, o ponto de vista crítico é aquele que vê o que existe da perspectiva do novo que ainda não nasceu, mas que se encontra em germe no próprio existente (Nobre, 2004, p. 11).

Germinando a partir desta perspectiva, a teoria crítica também apresentou frutíferas análises partindo da psicologia, ratificando a sua vocação para a interdisciplinaridade. Ao longo das gerações, esta relação desenvolveu-se de forma distinta. Se observamos a ênfase na psicanálise freudiana com Adorno, Horkheimer e Marcuse; temos Habermas, em um segundo momento, fundamentando-se em uma psicologia cognitivista (Whitebook, 2008). Mais recentemente, a teoria crítica tem voltado sua atenção para a psicologia por meio de uma aproximação da psicanálise de relações objetais, privilegiando uma abordagem intersubjetiva em relação à análise dos impulsos. Ao longo de seu desenvolvimento, a psicologia serviu de suporte para as análises sociais realizadas pelos frankfurtianos; entretanto, também foi alvo de algumas de suas críticas. Cabe ressaltar as críticas à fundamentação epistemológica de determinadas correntes da psicologia com o questionamento: até que ponto não são elas mesmas mais uma expressão refinada do que Adorno (1995, p. 155) chama de "barbárie"?

entendo por barbárie algo muito simples, ou seja, que, estando na civilização do mais alto desenvolvimento tecnológico, as pessoas se encontrem atrasadas de um modo peculiarmente disforme em relação a sua própria civilização - e não apenas por não terem em sua arrasadora maioria experimentado a formação nos termos correspondentes ao conceito de civilização, mas também por se encontrarem tomadas por uma agressividade primitiva, um ódio primitivo ou, na terminologia culta, um impulso de destruição, que contribui para aumentar ainda mais o perigo de que toda esta civilização venha a explodir. 
A barbárie enquanto psicologia pode ser exemplificada pela violência de seus pressupostos adaptativos e subjetivistas que negam o contexto flagrante de desigualdade social e naturalizam os indivíduos. Uma psicologia frequentemente alheia às "condições objetivas implicadas no sofrimento das pessoas nas mais variadas instituições e situações sociais" (Patto, 2012, p. 15), que encobre as barbáries de uma sociedade injusta, desigual e violenta. Em suma, uma psicologia que permitiria a repetição do horror maior, refutando a "exigência que Auschwitz não se repita" (Adorno, 1995, p. 119).

A reflexão acerca da barbárie inevitavelmente conduz ao fio da educação: a formação (Bildung) torna-se semiformação em uma cultura de condições materiais reificantes e deformadoras da humanidade. A desigualdade no acesso à formação apresenta-se como uma das faces desta barbárie. O avanço racional e desumano da tecnologia, em descompasso com o avanço social da humanidade, expresso pelos métodos empregados tanto em psicologia quanto em educação, é outra. De um modo geral, a possibilidade de uma consciência crítica é coibida pelo empecilho à reflexão. Em seus escritos sobre educação, Adorno (1995, p. 149) enfatizou a necessidade de "questionamentos de psicologia profunda" para compreensão da formação e da constituição da barbárie. Partimos dessa afirmação e nos voltamos para refletir: qual formação em psicologia é necessária para efetivação desta contribuição? Sem dúvidas, uma psicologia crítica acerca do seu próprio histórico de barbárie. Para isso, lembramos "que a exigência de que Auschwitz não se repita seja a primeira de todas, não apenas para a educação, mas para a psicologia e a humanidade" (Barros, 2003, p. 120; grifo nosso).

Embora não mais marcada pela experiência histórica do nacional-socialismo e da situação fascista como forma de governo, a tradição da teoria crítica se mantém latente nas discussões contemporâneas. Sua força interpretativa demonstra o potencial de diagnóstico (e também de prognóstico) da realidade social, seja pela reinterpretação das primeiras gerações em contextos presentes ou pelo seu prolongamento em gerações ulteriores. A teoria crítica se mantém como perspectiva fecunda para se pensar os temas aqui propostos: ciência; educação; psicologia; direitos humanos. O compromisso ideológico da psicologia oferece a realidade necessária para o debate com Horkheimer e Marcuse sobre a responsabilidade da ciência. A barbárie ainda presente faz com que as reflexões de Adorno sobre a formação se mantenham precisas. De um modo geral, os pressupostos epistemológicos de uma teoria crítica da sociedade também proporcionam os elos para reflexão em parceria com a Psicologia da Libertação de Martín-Baró, cuja inspiração marxista conduz à crítica do imperialismo na 
construção do conhecimento, mais detidamente, da psicologia enquanto ciência produzida na América Latina (Ibañez, 2011).

\section{Ciência e responsabilidade social}

Embora Horkheimer (1931/1999) proponha uma superação da querela entre filosofia e ciência, esta ainda aparece como uma constante na realidade da formação em psicologia. A perspectiva da filosofia como passado da psicologia ainda perpassa muitos círculos acadêmicos que fundamentam-se em perspectivas positivistas. Demarcando o necessário rompimento com "teorias [que] retratam o mundo; não contribuem com ele" (Rush, 2008), a teoria crítica apresenta uma refutação do pressuposto de neutralidade científica, apresentando um comprometimento com a realidade social. Seu potencial para transformação funciona como um norte para se pensar a necessidade de revisão teórica da psicologia, preparando o solo para reflexão acerca das possibilidades de um novo futuro para a psicologia na realidade latinoamericana:

\footnotetext{
o sentido não deve ser buscado na reprodução da sociedade atual, mas em sua transformação. Por isso, para o modo de julgar dominante a teoria crítica aparece como subjetiva e especulativa, parcial e inútil, embora ela não proceda nem arbitrariamente nem ao acaso. Como ela contraria o modo de pensar existente que permite a continuidade do passado favorecendo os interesses da ordem ultrapassada, e se opõe aos garantes de um mundo partidário, a teoria crítica aparenta ser partidária e injusta (Horkheimer, 1937/1975, p. 146).
}

Desde seu escrito seminal, a teoria crítica apresenta contribuições para uma responsabilização social da ciência a partir de sua contraposição a uma teoria tradicional. Sob uma clara influência da noção de fragmentação social, Horkheimer (1937/1975) advoga em defesa de um caráter histórico do pensamento científico. Para tanto, expõe o caráter ideológico, mantenedor do sistema capitalista, representado pela teoria tradicional que tem suas bases no pensamento cartesiano: "em nome de uma pretensa neutralidade da descrição a teoria tradicional resigna-se à forma histórica presente da dominação [...] em uma sociedade dividida em classes, a concepção tradicional acaba por justificar essa divisão como necessária" (Nobre, 2004, p. 38). O conceito tradicional de teoria persegue uma tendência puramente matemática, empregada de forma efetiva nas ciências naturais. Perspectiva, entretanto, também perpetuada por determinadas escolas das ciências sociais, pautando a construção de um conhecimento afastado de sua fundamentação histórica e cultural: "na medida em que o conceito de teoria é independentizado, como que saindo da essência interna da gnose, ou possuindo uma fundamentação a-histórica, ele se transforma em uma categoria 
coisificada e, por isso, ideológica" (Horkheimer, 1937/1975, p. 129). É necessária uma concepção de ciência que se perceba inserida no sistema da divisão social do trabalho, já que

tanto quanto a influência do material sobre a teoria, a aplicação da teoria ao material não é apenas um processo intracientífico, mas também um processo social. Afinal a relação entre hipóteses e fatos não se realiza na cabeça dos cientistas, mas na indústria (Horkheimer, 1937/1975, p. 130).

A aplicabilidade e a disponibilidade de determinado conhecimento apresenta-se na práxis social. Se sua relação com a sociedade é considerada como exterior à produção científica, a práxis se revela como desumana, pois ignora quaisquer componentes históricos da experiência dos sujeitos sociais, suas lutas e necessidades cotidianas. A perspectiva da teoria tradicional também concebe o sujeito como espectador da realidade, ratificando a miséria social por meio da parcialidade em defesa de uma sociedade dividida em classes. Nesse sentido, atentamos para a teoria tradicional como plano de fundo epistemológico de uma série de teorias psicológicas, que "concebem seus objetos enquanto entidades autossustentáveis, que possuem propriedades que não dependem da atenção da teoria” (Rush, 2008, p. 40).

Marcuse (1967/2009) também apresenta a sua compreensão acerca da responsabilidade da ciência, considerada como mais uma mercadoria no sistema do capital. O cientista é responsável direto pelo que é realidade a partir de suas descobertas, isto porque há um lugar e uma função da ciência na realidade social. Nesta perspectiva, ciência, sociologia e política apresentam-se como uma tríade que conduz à inerência entre a teoria e a prática do conhecimento. O que se observa, entretanto, é uma fragmentação de tais elementos, revelando o caráter destrutivo e regressivo de teorias que se propõem neutras, afastadas de sua determinação social: “sua própria 'indiferença quanto aos valores' torna a ciência cega para o que acontece com a existência humana" (Marcuse, 1967/2009, p. 162). A separação entre conhecimentos e valores transformou a ciência em parceira dos poderes que ameaçam a autonomia humana e frustram uma existência livre. Uma revisão da autonomia científica revela a necessidade de que a ciência se apresente como pensamento crítico, rompa com uma suposta neutralidade axiológica e enfatize a proteção da existência humana:

a ciência como um esforço humano continua a ser a mais poderosa arma e o instrumento mais eficaz na luta por uma existência livre e racional. Esse esforço estende-se para além do estudo, além do laboratório, além da sala de aula, e visa a criação de um ambiente, tanto social quanto natural, no qual a existência pode ser libertada de sua união com a morte e a destruição. Tal libertação não será um objetivo externo ou subproduto da ciência, mas antes a realização da própria ciência (Marcuse, 1967/2009, p. 164) 
Refletir sobre o compromisso da ciência nos conduz a questionar também o comprometimento da instituição universitária na construção deste conhecimento. A realidade que se impõe é a de uma produção científica ainda atrelada às tendências de uma teoria tradicional e restrita à academia. Os muros da universidade parecem ainda mais intransponíveis quando pensamos sobre a defasagem de uma produção voltada para a transformação social e para a reflexão crítica acerca da sociedade de classes, incapaz do reconhecimento das injustiças. Percebemos que "é difícil negar que as condições objetivas que geraram o fascismo persistem e que as instituições que deveriam fazê-lo não o fazem" (Patto; Crochík, 2012, p. 150). A educação e a psicologia formadas dentro destas instituições acabam tornando-se cúmplices da barbárie.

\section{Psicologia e barbárie}

Pensar a relação entre psicologia e barbárie nos exige uma dupla abordagem: de um lado, cabe-nos recuperar a memória histórica da psicologia enquanto ciência e profissão circunscrita ao domínio do pensamento positivista; de outro, apontar as rachaduras internas de um modelo científico que, "prisioneiro de seus próprios métodos, impõe um procedimento não-social às ciências sociais" (Matos, 1993, p. 7). De uma íntima relação com a filosofia à crise da subjetividade privatizada, a psicologia só é reconhecida como ciência autônoma após a criação do primeiro laboratório de psicologia experimental, coordenado por Wilhelm Wundt, na segunda metade do século XIX (Figueiredo; Santi, 2008). Frente ao embate metodológico conhecido como querela dos métodos, a psicologia assume seu vínculo com o positivismo quando se adequa aos procedimentos e à neutralidade pertencentes às ciências da natureza. Travestida de ciência neutra e centrada no indivíduo, caberia à psicologia emergente investigar, mensurar e categorizar os fenômenos psicológicos sem permitir que leituras ideológicas influenciassem a sua busca pela verdade. Todavia, é justamente a pretensa postura de neutralidade científica que conduz a psicologia às veredas da submissão ideológica:

\footnotetext{
a separação entre sociedade e psique é falsa consciência; ela eterniza categorialmente a clivagem entre sujeito vivo e a objetividade que impera sobre os sujeitos, mas que provém deles. Não se pode, entretanto, retirar a base dessa falsa consciência através de um decreto metodológico. Os seres humanos não conseguem reconhecer-se na sociedade, e esta não se reconhece em si mesma, porque eles são alienados entre si e em relação ao todo (Adorno, 2015, p. 74).
}

Apresentada de forma abstrata, a sociedade é tida como uma entidade "harmônica, que infelizmente passa por crises, mas que não é contraditória em sua essência, que paira acima e além dos homens e à qual estes se adaptam aos seus ambientes naturais" (Patto, 1987, p. 1). 
Nesse cenário, os psicólogos lidam com indivíduos cuja realidade histórica é limitada ao âmbito da abstração, através de teorias que universalizam aspectos pertencentes a um determinado contexto. Em um cenário onde a desigualdade e opressão limitam as possibilidades de ação humana, a ausência de uma postura crítica na psicologia contribui para uma produção científica que "não está dirigida à vida da coletividade nem satisfaz às exigências dos indivíduos, mas está orientada à exigência de poder de indivíduos e se encarrega também da penúria na vida da coletividade" (Horkheimer, 1937/1975, p. 142).

A orientação ideológica insciente da psicologia pode ser observada em diferentes momentos da história: do ajustamento de comportamentos desviantes à elaboração de laudos que legitimam tecnicamente a produção do fracasso social. Na América Latina, o descompromisso social da ciência se tornou evidente quando, em meio a regimes totalitários que silenciavam a esperança através da tortura, os psicólogos se limitavam a discutir sobre a psicometria. O cenário de opressão, violência institucionalizada e desesperança estava mais presente nas censuradas manifestações artísticas que nas produções científicas aclamadas pelos profissionais da época. No Brasil, a ausência de engajamento político beirou a falta de bom senso quando o Conselho Federal de Psicologia, recentemente criado, concedeu ao ditador Emílio Garrastazu Médici, patrono dos anos de chumbo, o diploma de psicólogo honorário (Hur, 2012). O caráter de guardiães da ordem imposta estava firmado não apenas no silêncio das representações políticas da categoria, mas também no terceiro capítulo da Lei 1.962/1962 que, ao regulamentar a profissão no país, definiu como funções privativas dos psicólogos o diagnóstico psicológico, a orientação psicopedagógica, a seleção e orientação profissionais e a solução de problemas de ajustamento. Em uma sociedade cujo predicativo se tornou a supressão da liberdade e o desencantamento do mundo, caber-nos-ia ajustar os indivíduos a um regime de obediência, silêncio e alienação?

Afastada da realidade social, a psicologia latino-americana permaneceu compenetrada em sua busca pelo reconhecimento científico. Os resquícios de um passado de submissão ressoavam na orientação intelectual adotada, através do apego ao conhecimento produzido aquém do cotidiano demarcado pela extrema pobreza, violência e inclusões perversas. Entretanto, produções marginais deram voz a novas formas de encarar o papel social do psicólogo, oferecendo diferentes respostas aos problemas sociais enfrentados pela população latina (Montero, 2004). Alvo de inúmeras críticas, esses autores advogavam em defesa do imperativo crítico como saída às práticas vigentes, uma vez que 
a crítica subverte o modo de ver as coisas; desencaixa os mecanismos de poder que sustentam posições estabelecidas e abre novas perspectivas ao conhecimento. Ela é parte da complexidade do mundo, usualmente tão difícil de aceitar. E em tal sentido a crítica é libertadora. Liberta das formas e modos estabelecidos como os únicos que permitem compreender o mundo, explicar nosso ambiente e que mantém certas hierarquias e relações baseadas na desigualdade e na submissão (Montero, 2004, p. 21 ; tradução nossa).

Mesmo com o fim da ditadura, a psicologia ainda se encontra inserida em um contexto onde a fragilidade democrática dos países latinos coloca em risco a efetivação dos direitos humanos e erradicação da desigualdade. Isto posto, a orientação crítica se configura enquanto uma promessa à libertação dos grupos historicamente oprimidos, mediante a construção de uma psicologia afinada à realidade e identidade latino-americanas.

\section{Enfrentando a miséria da psicologia}

No cenário latino-americano, a Psicologia da Libertação se destaca dentre os aportes teóricos que, através da crítica, enfatizaram as posturas ideológicas que impedem a psicologia de reconhecer a sua própria miséria. Nas palavras de seu fundador, Martín-Baró (1971/2015, p. $459^{2}$ ), "um pensamento crítico deve sê-lo por uma autenticidade dialética, consciente de sua imersão na história e, portanto, da negatividade que carrega em si mesmo", o que chama a nossa atenção para o compromisso ético-político firmado tanto na autocrítica da ciência quanto na contextualização social dos fenômenos e processos investigados.

No que tange à psicologia como ciência e profissão, a consciência de sua imersão histórica carrega em si um importante elemento para a ressignificação do papel social do psicólogo: o direcionamento de sua ação à libertação dos grupos historicamente oprimidos. A relação entre psicologia e libertação encontra-se, tradicionalmente, nas intervenções vinculadas à autonomia do sujeito frente transtornos orgânicos e funcionais (Martín-Baró, 1989/2011). Tendo em vista que a desconstrução de cadeias alienantes que limitam a autonomia individual convida os sujeitos a protagonizar a transformação de sua própria realidade, é imprescindível que a psicologia supere sua concepção individualista de libertação, atingindo a população que precisa escolher entre a sobrevivência e o atendimento psicológico. Para tanto, as práticas psicológicas devem ultrapassar os muros das instituições e alcançar as comunidades; articular-se aos direitos humanos; romper com as relações sociais reificadas; incentivar a recuperação da memória histórica. Todavia, seriam os psicólogos formados a partir dos atuais currículos capazes de assumir essa empreitada? 
Nossa argumentação se debruça sobre a tese de que o atual modelo de educação universitária, constituído em uma realidade alienada em si mesma, contribui para a composição de um perfil profissional alheio às necessidades dos condenados da terra e ao cenário de fragilidade democrática da América Latina. A nossa própria qualidade de universitários, nos afasta "vivencialmente das estruturas que condicionam e determinam mais profundamente os nossos povos, assim como nosso quehacer cotidiano" (Martín-Baró, 1974/1998, p. 131), uma vez que ainda nos debruçamos sobre discursos adventícios à identidade social latino-americana. Ao passo que permanecemos importando produções científicas de um contexto que não nos pertence, conduzimos nossos estudantes às perigosas consequências de atividades universitárias que empregam aproximações, enfoques e soluções acríticas que reafirmam a nossa situação de dependência histórico-cultural, conforme aponta Martín-Baró na obra supracitada. Se estamos propondo uma psicologia que ultrapasse os limites das instituições e consultórios, devemos esboçar um modelo de universidade que supere os limites da formação atada aos discursos ideologizados, orientando-se a partir das narrativas e necessidades do povo latino. Precisamos de uma formação profissional que nos possibilite atuar criativamente sobre o mundo, construindo produções autênticas e afinadas ao cenário em que nos encontramos

\begin{abstract}
necessariamente o pensamento autêntico, a palavra libertadora, a inteligência criativa tem que ser política. Política não indica mais que sua qualidade histórica, interpessoal, social: se situa em um presente aberto ao futuro e consciente do passado, um presente que continuamente deve ser recriado com os demais, para procurar novos horizontes. O pensamento criativo é dialógico e todo verdadeiro pensamento dialógico é necessariamente interpessoal, social, político (Martín-Baró, 1971/2015, p. 483).
\end{abstract}

No entanto, para que a passagem do pensamento alienado ao criativo seja possível, devemos impulsionar um modelo de formação em psicologia que se consagre enquanto um projeto emancipatório. Advogamos em defesa de uma graduação que permita ao estudante refletir criticamente sobre os limites e as possibilidades de reinvenção da profissão, isso porque, assim como Adorno (1995, p. 121), acreditamos que "a educação tem sentido unicamente como educação dirigida a uma autorreflexão crítica".

Influenciadas pelas provocações adornianas, defendemos que o papel social do psicólogo só poderá ser ressignificado quando a formação universitária for capaz de nos oferecer as bases necessárias para uma autorreflexão contínua e crítica acerca das consequências sociais de nossas intervenções e produções. Tendo a emancipação como objetivo último da graduação, devemos estar aptos a conscientizar nossos estudantes acerca 
das abordagens e práticas que justificam e omitem as inclusões perversas e violências cotidianas, uma vez que, "de um certo modo, emancipação significa o mesmo que conscientização" (Adorno, 1995, p. 143; grifo nosso). Definida em termos de um processo social e psicológico, a conscientização é "o movimento dialético, pessoal e comunitário do homem frente a realidade histórica em suas dimensões essenciais" (Martín-Baró, 1974/1998, p. 138). Enquanto processo psicológico, a conscientização possibilita a transformação ativa do mundo e a transformação reflexiva do ser humano; como processo social, ela se vincula ao comunitário e apresenta um caráter criativo e revolucionário. Portanto, uma educação voltada para a emancipação e conscientização se consagra em termos de uma educação política:

\footnotetext{
se o político é, pois, uma dimensão essencial da realidade humana, a conscientização será um simples mecanismo ideológico se não incidir imediata e diretamente sobre ela, [...] que consciência seria aquela que ocultara ou separara o homem e a comunidade precisamente daquelas forças, fatores, mecanismos e estruturas que determinam a organização de sua vida e a direção de seu destino? A ignorância mais perigosa é a daquele que crê saber (Martín-Baró, 1974/1998, p. 141).
}

Nesse cenário, para que o imperativo ético da educação seja a luta contra a barbárie, devemos insistir em uma formação apta a fortalecer as barricadas construídas pela resistência. Isso porque, se queremos impedir que a reprodução da barbárie seja o predicativo da atuação profissional do psicólogo, "a única concretização efetiva da emancipação consiste em que aquelas poucas pessoas interessadas nesta direção orientem toda a sua energia para que a educação seja uma educação para a contradição e para a resistência" (Adorno, 1995, p. 183).

\section{Psicologia - para quê?}

Com o fim da ditadura militar, o processo de redemocratização do Brasil trouxe consigo a promessa de um Estado fundamentado na Declaração Universal dos Direitos Humanos. A criação do Sistema Único de Saúde e, anos depois, do Sistema Único de Assistência Social são exemplos dos passos dados em direção à construção de políticas públicas capazes de atender as necessidades das maiorias oprimidas. A inserção de psicólogos nesses espaços tornou imperativa a transformação da identidade profissional, sobretudo no que se refere à mudança nas perspectivas teóricas que fundamentam as suas intervenções. $\mathrm{O}$ próprio currículo em psicologia modificou-se na tentativa de corresponder a esta demanda (Brasil, 2011). Todavia, não é raro encontrarmos cursos de graduação submetidos à mera aplicação técnica de conhecimentos importados, eximindo-se da tarefa crítica ou substituindo- 
a por novas técnicas pretensamente mais humanas - que recaem na perspectiva ideológica por não romperem com a abstração da sociedade:

\begin{abstract}
nas diversas vertentes técnico-científicas da Psicologia, a relação entre o profissional e o cliente é mediada pela técnica que, longe de ser neutra, faz do "cliente" um depositário de pressupostos que informa a ação do psicólogo e de outros profissionais. Certamente, a responsabilidade última por este estado de coisas não é da Psicologia tomada isoladamente, mas de uma sociedade que transforma a psique em mercadoria e faz do psicólogo seu mercador (Crochík, Patto, 2012, p. 142).
\end{abstract}

$\mathrm{Na}$ figura de mercador também se encontram as instituições de ensino superior, cada vez mais precarizadas e submissas às instituições privadas de financiamento de graduação e pesquisa. A submissão da graduação às exigências do capital rompe concretamente com a perspectiva de autonomia e criação cultural da universidade, que se converte em comércio: "o que se vende mesmo é um diploma, que só engrossa estatísticas mentirosas sobre a porcentagem da população brasileira com nível universitário superior e ilude seus possuidores quanto à aquisição de um passaporte poderoso para o mundo do sucesso pessoal" (Patto, 2012, p. 14). A formação no ensino superior torna-se a consagração de um estado social mantenedor de uma série de poderes que separam, distinguem e colocam aqueles com títulos de técnicos acima dos demais na sociedade, o que Martín-Baró (1974/1998) chama de "mandarinismo tecnocrático". O ensino não trabalha a favor da democratização de conhecimentos, mas da potencialização da distinção social (Bourdieu, 2015) por um recorte classista, seja ele insciente ou não:

\footnotetext{
certamente, nossas universidades constituem o vértice da instituição escolar, e cumprem a perfeição com sua tarefa de selar a distinção classista. Junto ao título que os define como técnicos, a universidade outorga a seus graduandos o poder para incorporar-se ao mandarinato social, ao clube dos poderosos, a seita dos privilegiados [...] Como falar de conscientização sócio-política se não temos consciência nem de quem somos nem de quem servimos? (Martín-Baró, 1974/1998, p. 137).
}

Nesse cenário, a educação para a resistência e a contradição é preterida pelas exigências do mercado. A uniformização do currículo de norte a sul do Brasil ignora as idiossincrasias locais e esquece que imaginação e criatividade são pressupostos de uma educação efetiva, voltada para a democracia e a concretização dos direitos humanos. Direcionada aos limites da aprendizagem técnica, a educação perde o seu potencial para a experiência (Erfahrung) e se redireciona às falsas experiências criativas: o que está posto não é a reinvenção do existente, de suas bases, mas a substituição de discursos opressores por novas - e imaginativas - formas de supressão das potencialidades humanas. 
Entretanto, é imperativo reconhecer os espaços que contribuem para a ruptura das cadeias alienantes que impossibilitam uma formação crítica e orientada para o compromisso social da ciência, uma formação para além do capital. Uma educação fundamentada na investigação, docência e proteção social compõe os pressupostos de uma libertação total do espaço universitário, pela efetivação de mecanismos complementares e estruturais, segundo Martín-Baró (1974/1998). A diversidade de procedimentos de pesquisa e a interdisciplinaridade constituem uma fonte necessária para o trabalho universitário para além das salas de aula, segundo Horkheimer (1931/1999). Se nas salas de aula o que se discute é a aprendizagem técnica; grupos de estudo, eventos acadêmicos e encontros sob as árvores do campus são espaços potenciais para que estudantes e professores possam alcançar maior liberdade de pensamento e produção. Isso porque, "muitas vezes um estudante recebe um aporte mais esclarecedor por meio de seu pequeno trabalho em um movimento estudantil do que em longas e pesadas horas em sala, laboratórios e provas" (Martín-Baró, 1974/1998, p. 146). A conscientização acerca dos limites e possibilidades da universidade diante deste cenário demonstra que o conhecimento acadêmico não prescinde da leitura de realidades, mas se constrói a partir da escuta. A abertura dos portões da universidade às maiorias populares não é apenas um caminho ao conhecimento efetivo da realidade local em que atuamos, mas também a porta de entrada para uma formação, de fato, emancipatória:

evidentemente não a assim chamada modelagem de pessoas, porque não temos o direito de modelar pessoas a partir do seu exterior; mas também não a mera transmissão de conhecimentos, cuja característica de coisa morta já foi mais do que destacada, mas a produção de uma consciência verdadeira. Isto seria inclusive da maior importância política; sua ideia, se é permitido dizer assim, é uma exigência política. Isto é: uma democracia com o dever de não apenas funcionar, mas operar conforme seu conceito, demanda pessoas emancipadas. Uma democracia efetiva só pode ser imaginada enquanto uma sociedade de quem é emancipado (Adorno, 1995, p. 141).

O contrário de uma formação emancipatória é uma formação calcada na amnésia social. Uma vez que ela nega sua própria implicação social, fundamenta-se na perda de memória histórica e no esquecimento da crítica. Ratificar o discurso crítico acerca da psicologia e da formação é promover a sua paulatina elaboração - evitar o seu esquecimento para, assim, evitar a sua confirmação como elemento, e documento, da barbárie.

\section{Considerações finais}

Seguindo caminho pela trilha aberta na aproximação entre psicologia e educação na luta contra a barbárie e com ênfase nos direitos humanos (Barros, 2003; 2013), encontramos 
na teoria crítica o solo fértil para se pensar a relação com a subjetividade no capitalismo tardio. Elegemos afinidades com a Psicologia da Libertação para direcionar esse diálogo à formação em psicologia e percebemos a importância da crítica, considerando-a como "práxis, atividade humana real, efetiva e transformadora" (Patto, 2012, p. 11). Aqui, ratificar esta atividade transformadora, constituída pela busca da raiz e dos compromissos sociais dos conhecimentos que acessamos, é a possibilidade de reinventar uma práxis historicamente determinada pelos interesses das classes dominantes e cega às necessidades das maiorias oprimidas.

Atentemos para o fato de que, se a universidade tem muito a dizer da barbárie, a barbárie, por sua vez, diz muito sobre a produção acadêmica - também sobre a educação e a psicologia. É imperativo perceber que a fala da academia sobre a barbárie é, em verdade, uma fala sobre si mesma. Esta fala desvela as portas fechadas aos sujeitos que são transfigurados em meros objetos, faz gritar a violência de seu silenciamento. A objetivação da verdade nos círculos acadêmicos, assim como a legitimação das diferenças sociais daí decorrente (Bourdieu, 2015), nos alerta para um intenso processo de dessimbolização acadêmica que oculta a criatividade e a subversão necessárias em nome de um discurso hegemônico (Barros; Macêdo, no prelo). Nesse sentido, concretiza-se a perspectiva de que "se as universidades não mudam, abrir as portas a todos (que não são todos e sim alguns mais) é o mesmo que multiplicar o número de opressores em potencial” (Martín-Baró, 1973/1998, p. 151).

Se, por um lado, parece sufocante o cenário de ratificação de uma vida danificada pela academia; por outro, as rachaduras que rompem com a fachada de totalidade da barbárie também merecem nossa atenção. Conduzir a psicologia ao exercício de "convidar os injustiçados para compartilhar os espaços comuns, de transformar o mundo que temos num mundo que desejamos" (Barros, 2013, p. 37) é uma forma de concretizar a possibilidade de uma profissão emancipadora. Sob as árvores, praças e salas de aula da Universidade Estadual de Feira de Santana, estamos redescobrindo o papel da escuta na formação em psicologia. Quando não direcionada às categorias psicopatológicas e aos comportamentos desviantes, a escuta é capaz de reconhecer, nas narrativas outrora sufocadas pelas opressões sociais e do conhecimento, as inúmeras formas de resistência à barbárie. Ao dialogar com crianças, comunidades indígenas e cidadãos em situação de rua, defrontamo-nos com espaços potenciais para a reinvenção do que é ser psicólogo na América Latina, no Brasil, no agreste baiano... Esses têm sido espaços que nos provam que 
um psicólogo que não desenvolver a capacidade de refletir sobre a ciência que pratica - ou seja, de refletir sobre a dimensão epistemológica e ética do conhecimento que ela produz e que ele reproduz - certamente soma, insciente, com o preconceito delirante, a opressão, o genocídio e a tortura, atitudes e condutas que, segundo Adorno, são constitutivas da barbárie (Mello; Patto, 2012, p. 20).

E nós escolhemos, por teimosia ou esperança, uma educação orientada para a contradição e resistência às tradicionais formas de agir e de pensar.

\section{NOTAS}

1 Graduandas em Psicologia pela Universidade Estadual de Feira de Santana (UEFS). E-mails: stefaniemacedo@gmail.com e t.almeidas@hotmail.com .

2 Todas as citações diretas à obra de Martín-Baró, excetuando-se Desafios e perspectivas da Psicologia Latinoamericana (1989/2011), foram traduções livres dos originais em espanhol.

\section{REFERÊNCIAS BIBLIOGRÁFICAS}

ADORNO, T. Educação e emancipação. São Paulo: Paz e Terra, 1995.

Sobre a relação entre sociologia e psicologia. In: ADORNO, T. Ensaios sobre psicologia social e psicanálise. São Paulo: Editora Unesp, 2015, pp. 71-135.

BARROS, C.C. A relação entre a psicologia e a educação na luta contra a barbárie. São Paulo: FEUSP, 2003 (Dissertação de Mestrado).

. Psicologia e educação para os direitos humanos. In: BARROS, C.C.; SEKKEL, M.C. (Org.). Licenciatura em psicologia: temas atuais. São Paulo: Zagodoni, 2013, pp. 21-41.

BARROS, C.C.; MACÊDO, S.A. Dos sentimentos de injustiça aos movimentos sociais: novos caminhos para a psicologia na teoria crítica. In: ANTUNES, D.C.; PISANI, M.M.; FERREIRA, I.R.; RIPA, R. (orgs.) As vicissitudes da experiência no mundo digital. Florianópolis: UDESC, 2017, pp. 58-73.

BOURDIEU, P. A distinção: crítica social do julgamento. 2. ed. rev. São Paulo: EdUSP; Porto Alegre, RS: Editora Zouk, 2015.

BRASIL. Resolução CNE/CES 5/2011. Institui as Diretrizes Curriculares Nacionais para os cursos de graduação em Psicologia. Diário Oficial da União, Brasília, 16 de março de 2011.

CUELLAR, E.B. Formación de psicólogas y psicólogos en América Latina: hacía una nueva razón ético-política para la humanidad. In: CUELLAR, E.B. (Org.). Formación en psicología: reflexiones y propuestas desde América Latina. Bogotá: ALFEPSI Editorial, 2015, pp. 17-40.

FIGUEIREDO, L.C.; SANTI, P.L.R. Psicologia, uma (nova) introdução: uma visão histórica da Psicologia como ciência. São Paulo: EDUC, 2008.

HORKHEIMER, M. (1931). A presente situação da filosofia social e as tarefas de um instituto de pesquisas sociais. Revista Praga, São Paulo, 1999, pp. 121-132.

(1937). Teoria tradicional e teoria crítica. In: BENJAMIN, W.; HORKHEIMER, M; ADORNO, T.; HABERMAS, J. Textos escolhidos. São Paulo: Abril, 1975, pp. 125-162. 
HUR, D.U. Políticas da psicologia: histórias e práticas das associações profissionais (CRP e SPESP) de São Paulo, entre a ditadura e a redemocratização do país. Psicologia (USP), São Paulo, v. 23, n. 1, pp. 69-90, 2012.

IBAÑEZ, L.C. A psicologia social de Martín-Baró ou o imperativo da crítica. In: GUZZO, R.S.L.; LACERDA JR, F. Psicologia social para América Latina: o resgate da psicologia da libertação. 2. ed. Campinas: Alínea, 2011, pp. 121-151.

MARCUSE, H. (1967). A responsabilidade da ciência. Scientice Studia, São Paulo, v. 7, n. 1, pp. 159-64, 2009.

MARTÍN-BARÓ, I. (1974). Concientización y currículos universitarios. In: Psicología de la liberación. Madrid: Editorial Trotta, 1998, pp. 131-159.

(1971). Del pensamiento alienado al pensamiento creativo. Teoría y crítica de la psicología. Morelia, v. 6, n. 1, pp. 457-486, 2015.

(1989). Desafios e perspectivas da Psicologia Latino-americana. In: GUZZO, R.S.L.; LACERDA JR, F. Psicologia social para América Latina: o resgate da psicologia da libertação. 2. ed. Campinas: Alínea, 2011, pp. 199-219.

MATOS, O. A Escola de Frankfurt: luzes e sombras do Iluminismo. São Paulo: Moderna, 1993.

MELLO, S. L.; PATTO, M.H.S. Psicologia da violência ou violência da Psicologia?. In: PATTO, M.H.S. (Org.). Formação de psicólogos e relações de poder: sobre a miséria da Psicologia. São Paulo: Casa do Psicólogo, 2012, pp. 17-22.

MONTERO, M. Relaciones entre psicología social comunitaria, psicología crítica y Psicología de la Liberación: una respuesta latinoamericana. Psykhe, Santiago, v. 13, n. 2, pp. 17-28, 2004.

NOBRE, M. A teoria crítica. São Paulo: Zahar, 2004.

PATTO, M.H.S. Psicologia e Ideologia: uma introdução crítica à Psicologia Escolar. São Paulo: T.A Queiroz, 1987.

Introdução. In: PATTO, M.H.S. (Org.). Formação de psicólogos e relações de poder: sobre a miséria da psicologia. São Paulo: Casa do Psicólogo, 2012, pp. 8-16.

PATTO, M.H.S.; CROCHÍK, J.L. Pedindo socorro à parede. In: PATTO, M.H.S. (Org.). Formação de psicólogos e relações de poder: sobre a miséria da psicologia. São Paulo: Casa do Psicólogo, 2012, pp. 137-152.

RUSH, F. As bases conceituais da primeira teoria crítica. In: RUSH, F. Teoria crítica. Aparecida, São Paulo: Ideias \& Letras, 2008, pp. 31-66.

WHITEBOOK, J. A união de Marx e Freud: a teoria crítica e a psicanálise. In: Rush, F. Teoria crítica. Aparecida, São Paulo: Ideias \& Letras, 2008, pp. 105-134. 